\title{
Physico-Chemical and Biological Study of Marpha Pond District Anuppur, Madhya Pradesh, India
}

\author{
Amar Bahadur Singh \\ (Scientific Officer), Biology/Serology- Section, State Forensic Science Laboratory Civil Line, \\ University Road Sagar Madhya Pradesh - 470001, India
}

\begin{abstract}
The Present paper study is Physico-chemical analysis of Marpha Pond water. The study is carried out January 2014 December 2014. The Physico-chemical properties of water have been discussed. The pond is not much polluted. Hence it can be used as potable water in Marpha Pond district Anuppur, Madhya Pradesh.
\end{abstract}

Keywords: Physico-chemical, Marpha Pond, Anuppur

\section{Introduction}

The study site lies between $23^{\circ} 6^{\prime} 0^{\prime \prime} \mathrm{N}$ Latitude and $81^{\circ} 41^{\prime} 1^{\prime \prime}$ E Longitude. Anuppur District situated in the north eastern part of Madhya Pradesh. This District came into existence on 15th August 2003 by re-organising Shahdol District. Anuppur District has total area of $3701 \mathrm{Sq} . \mathrm{km}$., extends 80 $\mathrm{km}$ from east to west and $70 \mathrm{~km}$ from north to south. District Anuppur is surrounded by Koria District (C.G.) in east, Shahdol \& Umaria district in west. Shahdol district in nortand Dindori (M.P.) Bilaspur (C.G.) in the south. The Marpha pond is perennial one. The area of pond is nearly 17 Hactare. It is Siutated inside of the city. According to local residents it was digged by Pandavas but some people also says that this pond had been made by the authority of municipality before 100 years ago. During the time of Hindus festivals all the statues of Deviand Deotas are disposed in to the pond, so due to these activities water is becomes polluted. The fisheries department also culture the fishes. Hence this pond has been under taken during present study for physicochemical analysis of water along with fish Culture. (Figure 1).

Biological study in water is very important life supporting material. Every living organism needs water, without which neither the life nor any development is possible. Thus it is very much essential for a healthy growth. But it may become harmful for life, if one uses water polluted with harmful or with toxic substances and poor sanitation. (Gupta and Gupta 2000, Mishra, et al. 2009, Sirajudeen et al.2014, Kumar and Kumar 2015) Water quality parameters provide the basis for judging the suitability of water for its designated uses and to improve existing conditions. For optimum development and management for the beneficial uses, current information is needed which is provided by water quality programmes (Lloyd, 1992). We depend on water for domestic needs, irrigation, sanitation and disposal of wastes. The quality and quantity of surface water bodies like lakes and tanks depend upon the climate, catchments, geography of the area and the inputs and outputs both natural and manmade (Gray1994). The water quality of lakes can be degraded due to microbiological and chemicals contaminants. In water natural impurities are in very low amounts. Lakes, dams, rivers are important source of fresh water.

The quality of water is described by its physical, chemical and microbial characteristics but if some correlations were possible among these parameters, then significant ones would be fairly useful to indicate the quality of water. The study of important, because fluctuation in the water quality has an influence on the biotic communities (Aher and Mane 2007). This information is important to be communicated to the general public and the Government in order to develop policies for the conservation of the precious fresh water resources (Ali et al., 2000). The aims of this study were designed to monitor seasonal variation in water quality parameter of Marpha Pond so as to assess its status and suitability through the portability and aquaculture point of view and to compare observed levels of studied parameters with the corresponding WHO and BIS guidelines values for drinking-water quality and Pisciculture. 


\section{International Journal of Science and Research (IJSR) \\ ISSN (Online): 2319-7064}

Index Copernicus Value (2013): 6.14 | Impact Factor (2015): 6.391
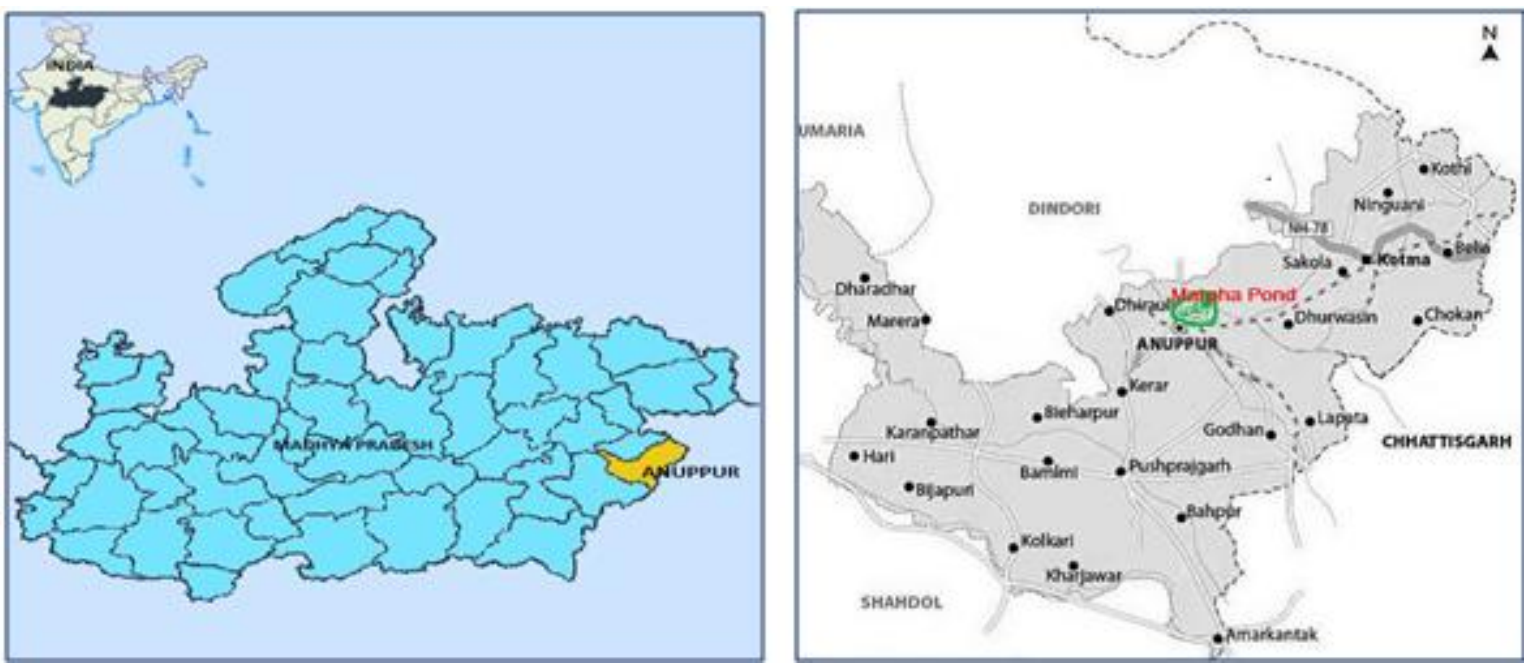

Figure 1: Location Map of Study area District Anuppur in Presenting Marpha Pond

\section{Materials and Methods}

During Present Study of Physico-chemical parameters were carried out during the period of January 2014 to December 2014. By considering the morphometry and human activities sampling sites were selected at different places along the tanks, From all the four stations of pond, water samples were collected from the periphery at about 1 to 1.5 meters depth fortnightly. The water samples were collected in plastic cans of 2-3 lit. Capacity and brought to the laboratory to study various parameters. Temperature and $\mathrm{pH}$ were recorded at the time of sample collection using portable kit. The determination of dissolved oxygen, free carbon dioxide, hardness, chlorides, total alkalinity, inorganic phosphate and nitrate were analysed in the laboratory as per the standard procedure and metrology described by APHA, AWWA, WPCF (1989).

\section{Results and Discussion}

The result of Physical properties of water from Marpha Pond was given in Table 1and the results of Chemical properties of water from Marpha Pond was shown in Table 2.

Table 1: Physical Parameters of Marpha Pond, District Anuppur, Madhya Pradesh.

\begin{tabular}{|c|c|c|c|c|}
\hline Months & $\begin{array}{c}\text { Temperature } \\
\left({ }^{\circ} \mathrm{C}\right)\end{array}$ & $\begin{array}{c}\text { Turbidity } \\
(\text { NTU })\end{array}$ & $\begin{array}{c}\text { Transparency } \\
(\mathrm{cm})\end{array}$ & $p H$ \\
\hline Jan. & 19.3 & 2.26 & 41.7 & 7.36 \\
\hline Feb. & 29.1 & 2.9 & 38.5 & 7.37 \\
\hline Mar. & 29.5 & 2.96 & 37.4 & 7.39 \\
\hline Apr. & 30.6 & 1.2 & 36.3 & 7.4 \\
\hline May & 33.2 & 1.45 & 30.2 & 7.37 \\
\hline Jun. & 32.9 & 1.65 & 25.8 & 7.27 \\
\hline Jul. & 30 & 1.74 & 24.6 & 7.32 \\
\hline Aug. & 29.8 & 1.56 & 25.5 & 7.44 \\
\hline Sept. & 29.6 & 1.9 & 27.5 & 7.48 \\
\hline Oct. & 29.3 & 0.85 & 26.8 & 7.44 \\
\hline Nov. & 28.1 & 0.68 & 29.2 & 7.4 \\
\hline Dec. & 19.1 & 1.54 & 30 & 7.41 \\
\hline
\end{tabular}

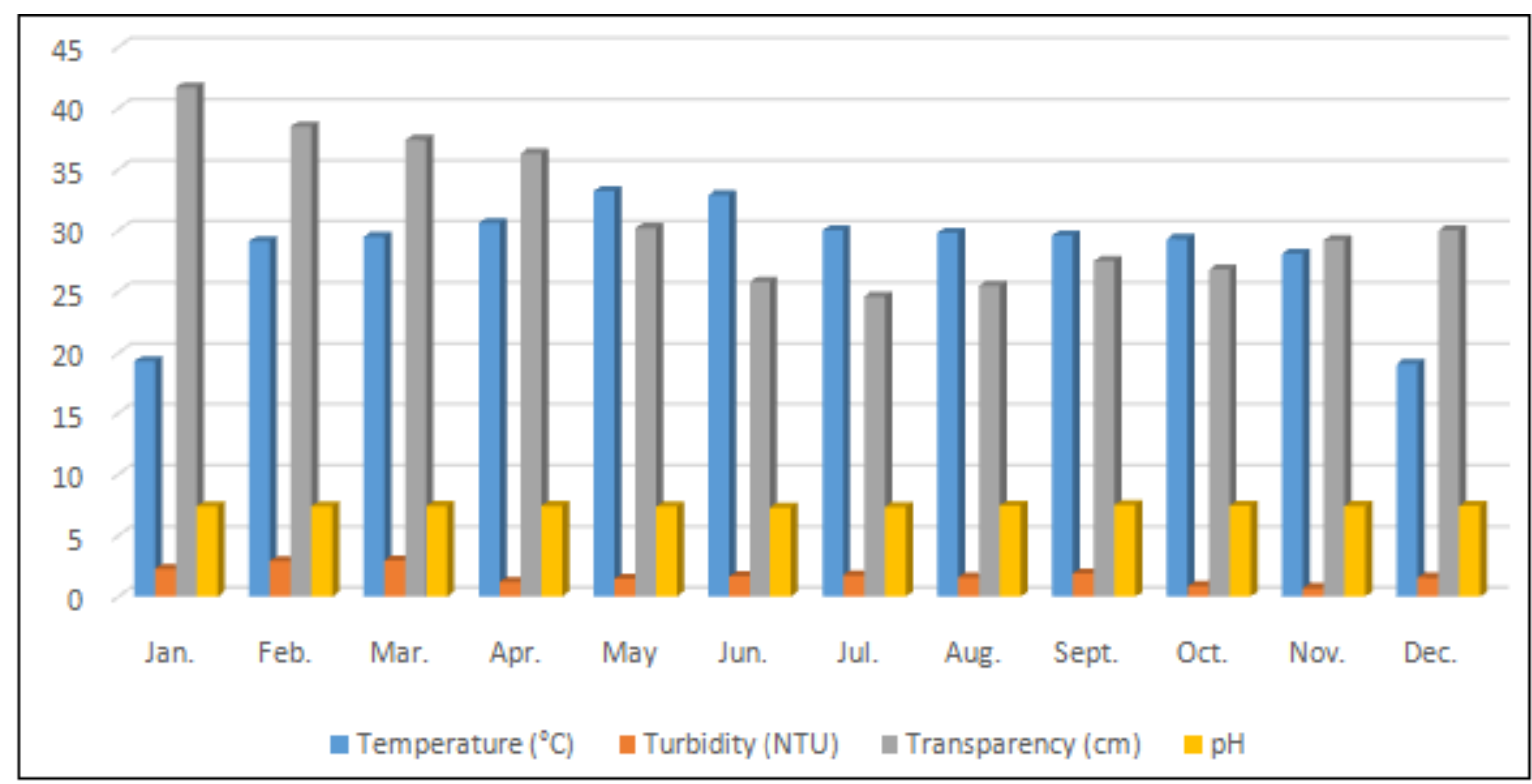

Graph 1: Physical Parameters of Marpha Pond, District Anuppur, Madhya Pradesh.

\section{Volume 5 Issue 6, June 2016 www.ijsr.net}

Licensed Under Creative Commons Attribution CC BY 


\section{International Journal of Science and Research (IJSR) \\ ISSN (Online): 2319-7064}

Index Copernicus Value (2013): 6.14 | Impact Factor (2015): 6.391

Table 2: Chemical Parameters of Marpha Pond, District Anuppur, Madhya Pradesh (values are in mg/l)

\begin{tabular}{|c|c|c|c|c|c|c|c|}
\hline Months & Dissolved Oxygen & Free $\mathrm{CO}_{2}$ & Alkalinity & Hardness & Phosphate & Nitrate & Chloride \\
\hline Jan. & 8 & 4.37 & 153 & 176 & 0.24 & 0.19 & 37.69 \\
\hline Feb. & 7.3 & 4.52 & 159 & 170 & 0.24 & 0.15 & 32.1 \\
\hline Mar. & 6.5 & 4.63 & 165 & 161 & 0.31 & 0.23 & 55.29 \\
\hline Apr. & 5.4 & 4.95 & 138 & 187 & 0.35 & 0.24 & 45.39 \\
\hline May & 5.2 & 5.7 & 130 & 232 & 0.36 & 0.29 & 40.36 \\
\hline Jun. & 5.6 & 6.09 & 116 & 161 & 0.34 & 0.33 & 37.62 \\
\hline Jul. & 5.8 & 4.91 & 80 & 84 & 0.32 & 0.37 & 26.68 \\
\hline Aug. & 6.2 & 5.22 & 87 & 73 & 0.48 & 0.35 & 30.99 \\
\hline Sept. & 6.3 & 5.24 & 97 & 115 & 0.4 & 0.31 & 32.09 \\
\hline Oct. & 7.2 & 4.95 & 116 & 137 & 0.28 & 0.28 & 34.47 \\
\hline Nov. & 7.7 & 4.5 & 129 & 126 & 0.25 & 0.27 & 39.16 \\
\hline Dec. & 8.1 & 4.18 & 148 & 285 & 0.27 & 0.23 & 44.66 \\
\hline
\end{tabular}

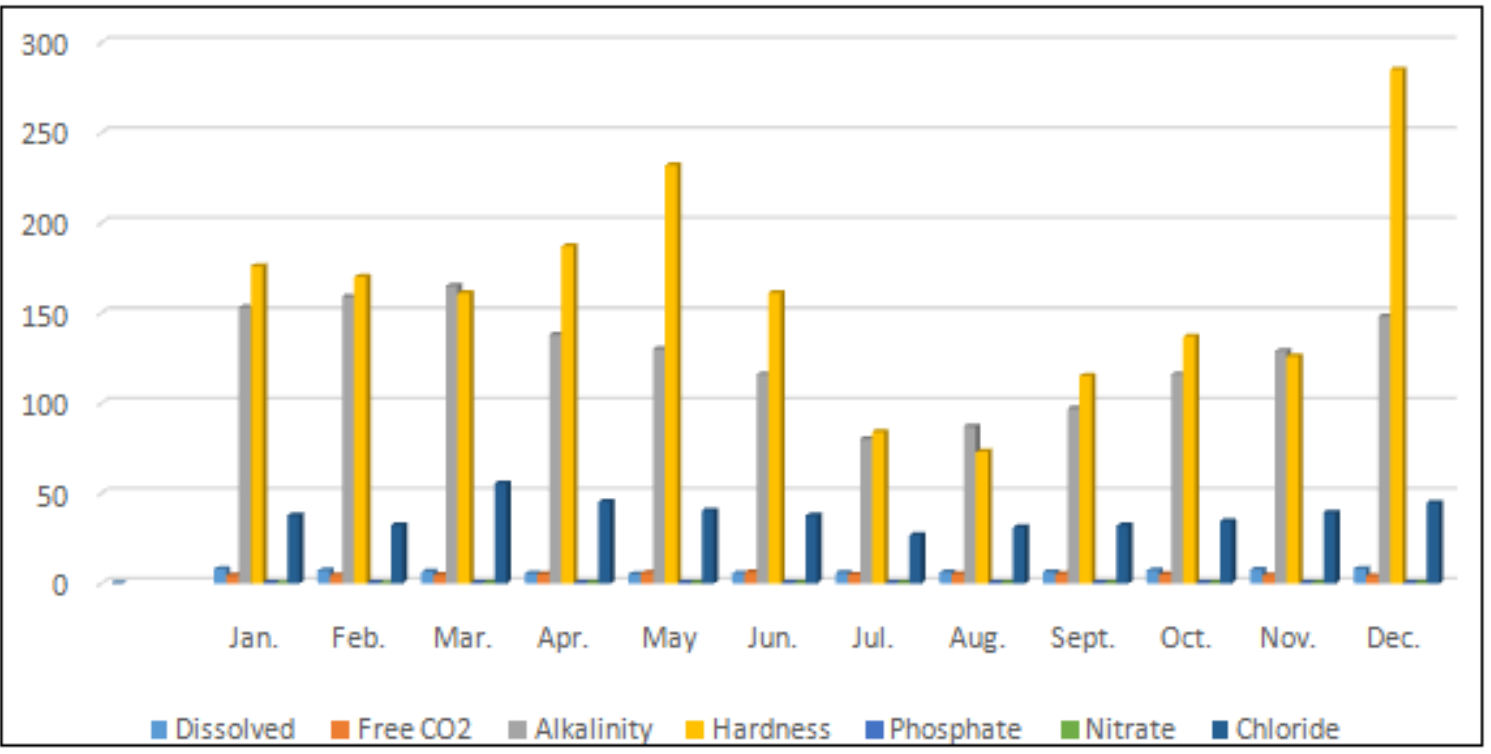

Graph 2: Chemical Parameters of Marpha Pond, District Anuppur, Madhya Pradesh

Turbidity is an important limiting factor in the productivity of freshwater ecosystems. It was recorded within the range from 0.68 to 2.95 NTU. Transparency is the property of water by which it allows light to pass. Light is an essential factor in freshwater environments for survival of hydrophytes and acts source of oxygen as a by Product of photosynthesis. Transparency was varied from $24.06 \mathrm{~cm}$ to $41.7 \mathrm{~cm}$. The $\mathrm{pH}$ of the water samples was alkaline throughout study period. $\mathrm{pH}$ was recorded within the range from 7.27 to 7.48. Minimum $\mathrm{pH}$ was observed in the month of March and maximum in the month of June. $\mathrm{pH}$ range within 6.0 to 8.5 range is good for culturing tropical fish species (Huett, 1977) and, it is the recommended levels for drinking water (WHO, 1984): Federal Environmental protection Agency (FEPA) recommended $\mathrm{pH}$ 6.5-8.0 for drinking and 6.0-9.0 for aquatic life. The cheap rate of photosynthetic activities reduces the assimilation of carbon dioxide and bicarbonates which are eventually responsible for increase in $\mathrm{pH}$, the low oxygen values coincided with high temperature during the summer month. The factors like temperature bring about changes in the $\mathrm{pH}$ of water. The higher $\mathrm{pH}$ values observed suggests that carbon dioxide, carbonate- bicarbonate equilibrium is affected more due to change in Physico-chemical condition Change in $\mathrm{pH}$ is due to discharge of agricultural wastes, human anthropogenic activities and surface runoff.
The dissolved oxygen was recorded within the range from 5.2 to $8.1 \mathrm{mg} / \mathrm{l}$ Minimum dissolved oxygen was recorded in the month of May and maximum in the month of December. The amount of dissolved oxygen in water was not constant but fluctuates, depending on temperature, depth, wind and amount of biological activities such as degradation dissolved oxygen concentration decreased due to high temperature. The dry season showed a significantly higher oxygen content than the wet at Kangimi reservoir, Kaduna state Nigeria.

The free carbon dioxide content in the water samples of Marpha Pond was within the range from 4.18 to $6.09 \mathrm{mg} / \mathrm{l}$. High content of free carbon dioxide was recorded in the month of June and minimum in December also recorded the similar results regarding free $\mathrm{CO} 2$ content from freshwater bodies. Alkalinity in the water samples of Marpha Pond varied from 80.0 to $165.0 \mathrm{mg} / \mathrm{l}$. Minimum alkalinity was recorded in July and maximum in February.

The hardness was fluctuated from 73.0 to $285.0 \mathrm{mg} / \mathrm{l}$. The minimum hardness was recorded in the month of August and maximum in December. The similar results were obtained by Ravichandran et al. (2009) from the study of ponds from Phosphate content was fluctuated between 0.27 to $0.48 \mathrm{mg} / \mathrm{l}$. It was observed as minimum in December and maximum in August. The phosphate content in any water body was quite opposite in relation to dissolved oxygen and phytoplankton

\section{Volume 5 Issue 6, June 2016} www.ijsr.net 


\section{International Journal of Science and Research (IJSR) \\ ISSN (Online): 2319-7064}

Index Copernicus Value (2013): 6.14 | Impact Factor (2015): 6.391

population. Many earlier workers have also reported similar findings (Ghavzan et al., 2006).

Nitrate content in the water was recorded within the range from 0.15 to $0.37 \mathrm{mg} / \mathrm{l}$. Minimum nitrate content was observed in the month of February and maximum in July. The Chloride content in water samples was recorded from 26.68 to $55.29 \mathrm{mg} / \mathrm{l}$. Minimum Chloride content was recorded in the month of July and maximum in March. Chourasia and Adoni (1985) also found similar behavior of chlorides in their studies on Sagar Lake with summer maxima and winter minima.

Almost all parameters during the present study meet the water quality norms as per BIS New Delhi. Now it is clear that, the tank is not polluted by human anthropogenic activities and agricultural runoff from surrounding areas. Hence, it is appropriate for human consumption. Moreover, pond is used for irrigation, fishery and domestic purposes. As water is not contaminated, it is potable.

\section{Acknowledgement}

Author is thankful to Dr. Mohammad Husain, Principal Govt. Nehru P.G. College Burhar District Shahdol, (M.P.) and Dr. A.A. Khan Retd. Professor and Head Dept. of Botany Govt. Girls P.G. College Rewa (M.P.) for valuable suggestion and carried out this work.

\section{References}

[1] Aher, S.K. Mane, U.H. and Pawar, B.A. (2007). A study on physico-chemical parameters of Kagdipura Swamp in the relation to pisiculture near Aurangabad, Maharashtra

[2] APHA, AWWA and WPCF, (1989). Standard method of examination of water and waste water, $20^{\text {th }} \mathrm{Edn}$., American Public Health Association, Washington DC. USA. Pp. 1213.

[3] Ali M. A., Salam A., Azeem M., Shafique and Khan, B.A. (2000). Studies on the effect of seasonal variations on physical and chemical characteristics of mixed water from Rivers Ravi and Chenab at union site in Pakistan. J. Res. B. Z. Univ. Multan, 2: 1-17.

[4] Arvind, Kumar (1995). Some limnological aspects of the freshwater tropical wetland of santhalPargana (Bihar) India. J. Env. And Poll. 2(3) : 137-141.

[5] Gray, N.F. (1994). Drinking water quality problems and solutions Chichester, UK: John Wiley and Sons.

[6] Gupta, S.K., Gupta, R.C., Gupta, A.B., Seth, A.K., Bassin, J.K. and Gupta, A. (2000). Recurrent acute respiratory infections in areas with high nitrate concentrations in drinking water. Environ Health Perspect. 108 : 363-366.

[7] Kumar, Ravindra and Jha, Arvind Kumar (2015). Physico-chemical studies on Kamla River Water, IJARCSSE, 5(5): 1411-1415.

[8] Lloyd, R. (1992): Pollution and Fresh Water Fish, Fishing News Books.

[9] Mishra, Deepti, Mudgal, Manish, Khan, MohdAkram, PrabhaPadmakaran and Chakradhar, B. (2009). Assessment of ground water quality of Bhavnagar region (Gujarat). Journal of Scientific \& Industrial Research, 68: 964-966.

[10] Sirajudeen, J and Yahith, R. Abdul (2014). Water quality assessment of groundwater resources between Tamilnadu and Pondicherry states, India. World Journal of Pharmacy and Pharmaceutical Sciences, 3(7):881893. 